\title{
Effects of extremely low-frequency electromagnetic fields (ELF-EMF) exposure on B6C3F1 mice
}

\author{
Guangying $\mathrm{Qi}^{1,2} \cdot$ Xiaoxu Zuo $^{1} \cdot$ Lihua Zhou $^{1,2} \cdot$ Eriko Aoki $^{2} \cdot$ Aya Okamula $^{2}$. \\ Mika Watanebe $^{2}$ Haipeng Wang ${ }^{1} \cdot$ Qiuhui $\mathrm{Wu}^{1} \cdot$ Huiling $\mathbf{L u}^{1} \cdot$ Handan Tuncel $^{3}$. \\ Hiromitsu Watanabe $^{4} \cdot$ Sien Zeng ${ }^{1}$. Fumio Shimamoto ${ }^{2}$
}

Received: 10 February 2015/Accepted: 6 April 2015/Published online: 5 May 2015

(C) The Japanese Society for Hygiene 2015

\begin{abstract}
Objective Long-term exposure study was conducted to investigate the effects of extremely low-frequency electromagnetic field on the tumor promotion process and fertility.

Methods Ten pregnant C57BL/6NCrj mice were exposed to $50 \mathrm{~Hz}$ field $500 \mathrm{mG}$ for 1 week ( $12 \mathrm{~h}$ per day), and 24 male and 42 female B6C3F1mice born from them were further exposed up to 15.5 months. As a control group, 10 pregnant mice were bred without exposure, and 30 produced male and 32 female mice were observed without exposure for the same period.

Results Mean body weights of exposed groups of male and female mice were decreased significantly than those of the control groups. In exposed mice, there was no increased incidence of liver and lung tumor. In female mice, the incidence of chronic myeloid leukemia [3/42 (7\%)] in the exposed group was significantly greater than in the control
\end{abstract}

G. Qi, X. Zuo, L. Zhou contributed equally to this work.

Sien Zeng

zse@glmc.edu.cn

Fumio Shimamoto

simamoto@pu-hiroshima.ac.jp

1 Department of Physiopathology and Gastrointestinal Surgery, Guilin Medical University, Guilin 541004, Guangxi, China

2 Department of Health Sciences, Faculty of Human Culture and Science, Prefectural University of Hiroshima, Minami-ku, Hiroshima 734-8558, Japan

3 Department of Biophysics, Cerrahpasa Medical Faculty, Istanbul University, Istanbul 34303, Turkey

4 Department of Research Institute for Radiation Biology and Medicine, Hiroshima University, Minami-ku, Hiroshima 734-8551, Japan group. The size of seminiferous tubules in the EMF exposed groups were significantly less than the control group. Conclusions These data support the hypothesis that longterm exposure of $50 \mathrm{~Hz}$ magnetic fields is a significant risk factor for neoplastic development and fertility in mice.

Keywords ELF-EMF · Long-term exposure - Chronic myeloid leukemia $\cdot$ Fertility $\cdot$ B6C3F1 mice

\section{Introduction}

EMF is a major environmental concern, and may constitute a risk to human health even at current pollution levels [1]. Each electrical home appliance from kitchen stove to television is an EMF source which may affect human health. An association between residential extremely lowfrequency electric and magnetic fields and childhood leukemia was first reported in 1979 by Wertheimer and Leeper [2]. Recent studies showed that magnetic fields had association with risk of childhood leukemia [3, 4]. Although many epidemiological studies examined the relationship of childhood cancer to occupational exposure of parents to magnetic/electromagnetic field [5, 6], the basis for such associations remains unexplained. Studies of carcinogenicity in animals almost do not support the risk for childhood leukemia [7]. However, a study showed that incidence of lymphoma significantly increased in mice chronically exposed to very strong low-frequency electromagnetic field [8]. On the other hand, some studies have shown the effects of EMF on fertility. Cell phone use negatively affects sperm quality in men [9] and ELF-EMF (extremely low-frequency electromagnetic fields) has detrimental effects on female reproductive system in mice by decreasing the number of flushed blastocysts and 
increasing the height of fallopian tube epithelial cells [10]. In contrast, some studies showed that exposure to ELFEMF did not induce any adverse effects on spermatogenesis and reproductive capacity in experimental animals and human [11]. This chronic exposure study was conducted to investigate the effects of extremely low-frequency electromagnetic fields on the tumor promotion process and fertility in mice.

\section{Materials and methods}

\section{Animals and Experimental protocol}

Twenty late pregnant C57BL/6NJ female mice which mated with $\mathrm{C} 3 \mathrm{H} / \mathrm{HeNJ}$ male mice were purchased from Charles River Japan. Mice were housed in wire cages in a standard conditioned room with a $12 \mathrm{~h}$ light and dark cycle and at $23 \pm 2{ }^{\circ} \mathrm{C}$ and $50 \pm 10 \%$ humidity, with free access to diet and drinking water. The animals were cared for in compliance with the principles and guidelines of Ethical Committee for Animal Care, in accordance with the Japan National Law on Animal Care and Use. Ethical Committee for Animal Care of the Prefectural University of Hiroshima has approved the experiments undertaken. Body weights were recorded every 4 weeks. 10 mice were exposed to $50 \mathrm{~Hz}$ field $500 \mathrm{mG}$ for 1 week (12 h per day) and produced 24 males and 42 female B6C3F1 mice. Then, 66 mice were continuously exposed to the same condition until 15.5 months after birth. In control group, 10 pregnant mice were bred without exposure, and then 30 male and 32 female offspring mice were equally observed without exposure for the same period. In the exposed and control group, weights of mice were measured monthly, respectively. All the offspring mice were sacrificed 15.5 months after birth. And the below tissue were examined macroscopically: all skin, eye, mammary gland, pituitary gland, brain, trachea, lung, thymus, heart, aorta, esophagus, stomach, intestine, liver, pancreas, gallbladder, salivary gland, kidney, ureter, urinary bladder, thyroid gland, adrenal gland, spleen, kidney, urinary bladder, ovary, testis, epididymides, uterus, vagina, mesenteric lymph nodes, paraaortic lymph nodes, and bone marrow (Fig. 1).

\section{Histological analysis}

For pathology analysis, 4- $\mu \mathrm{m}$ thick sections of formalin fixed, paraffin-embedded tissues were prepared. After hematoxylin and eosin staining, the sections of each slide were examined under a light microscope (Olympus, Japan). The incidence of tumors was studied.

\section{Morphometrical analysis of testis}

We randomly selected 30 seminiferous tubules for each testis of control and $500 \mathrm{mG}$ exposed mice. The diameters of the seminiferous tubules were measured by using light microscopy.

\section{Statistical analysis}

The Statcel software package (KaleidaGraph Version 4.1) was used for analysis. The $\alpha^{2}$ test, Fisher's exact test and $t$ test (Statcel, The useful Addin Forms on Excel, 2nd ed.) were used to compare data between the two groups. Statistical analysis was performed between the exposed group and the control group, using the $t$ test, Chi square, and Fisher's exact method. The significant level was set at $5 \%$ for each analysis.

\section{Results}

\section{The change of the weights of body and various} organs in $\mathrm{B} 6 \mathrm{C} 3 \mathrm{~F} 1$ mice

Significant difference was detected in the body weight of the mice between the exposed and the control group. The male body weights of the exposed group were significantly decreased than those of control group from 6 to 15.5 months $(P<0.01$, Fig. 2$)$. The female body weights of the exposed group were significantly decreased than those of the control group from 4 to 14 months $(P<0.01$, Fig. 2). Table 1 shows the weight of various organs in the mice from the exposed group and the control group. The hepatic weights of the exposed group were significantly decreased than those in the control group (Table 1). Table 1 showed that the testicular weights of the EMF exposed group mice $(0.11 \pm 0.021 \mathrm{~g})$ were significantly decreased than the control group mice $(0.12 \pm 0.030 \mathrm{~g})$, $(P<0.01)$. However, the testicular weights were not significantly different between the exposed group and the control group mice when two groups of mice were standardized with the average body weight $(50 \mathrm{~g})$ (Table 2$)$.

\section{Incidence of tumors in various organs of B6C3F1 mice}

Table 3 shows the results of incidence of tumors in various organs of $\mathrm{B} 6 \mathrm{C} 3 \mathrm{~F} 1$ mice between the control and exposed group. The tumors of liver and lung were mainly found in male mice (Table 3; Fig. 3A) but there is no significant difference in incidence of tumors between control and exposed group of male mice. On the other hand, chronic myelogenous leukemia was found in bone marrow of 3 female exposed mice $(7 \%)$ (Table 3; Fig. 3B). In the 
Fig. 1 Flow chart of the experiment

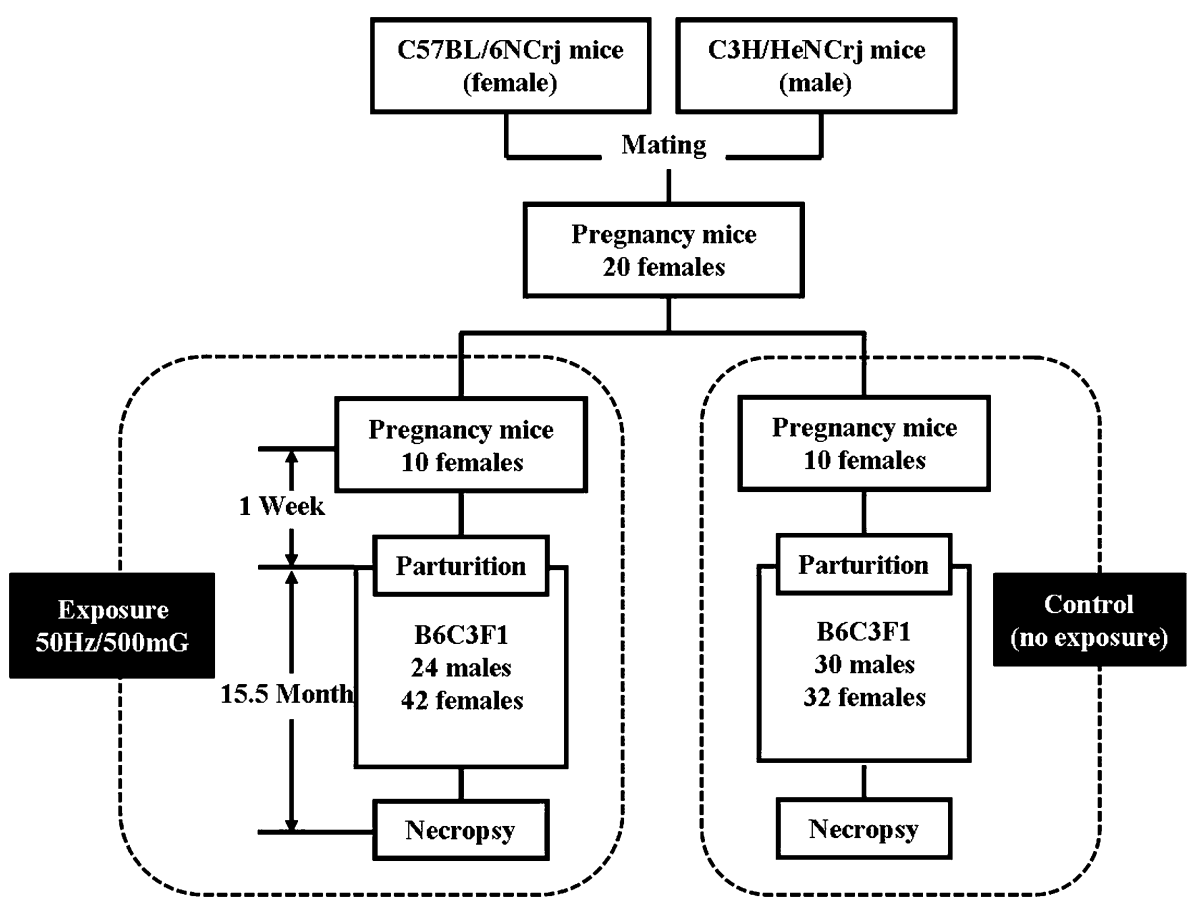

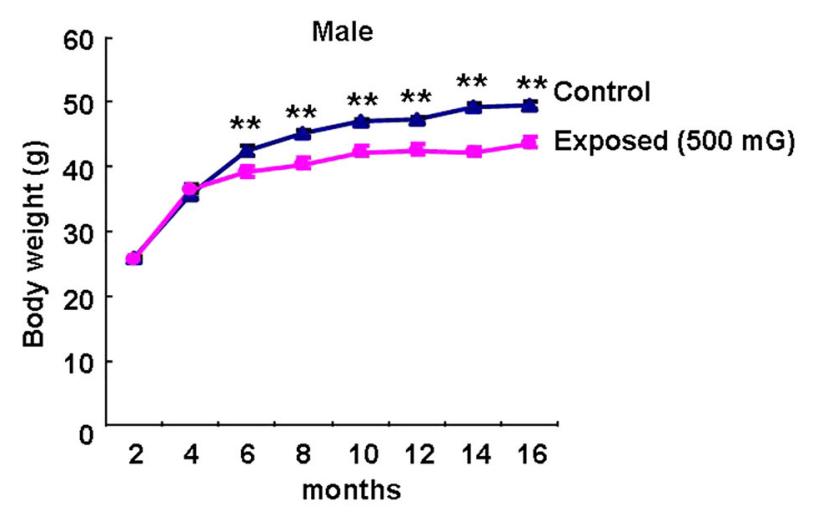

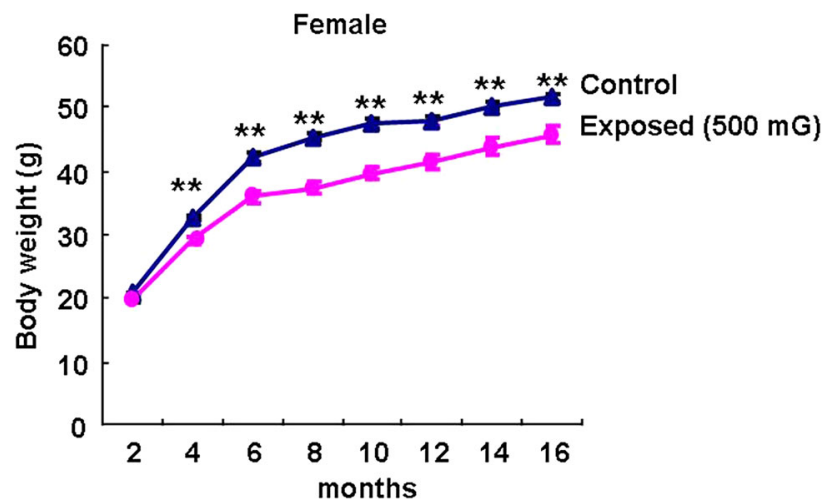

Fig. 2 Change of body weights in the control and EMF exposed B6C3F1 mice. Body weights in the control and EMF exposed B6C3F1 male and female mice. **Significantly different from two groups at $P<0.01$ control group, leukemia was not found (Table 3). In incidence of other tumor types, there was no significant difference between control and exposed group.

\section{The size of seminiferous tubules of $\mathrm{B6C3F1}$ male mice}

Table 4 shows the results of sizes of seminiferous tubules in B6C3F1 mice between control and exposed group. When male B6C3F1 mice were exposed with $500 \mathrm{mG}$ EMF, the sizes of seminiferous tubules were significantly smaller than the control groups $(197.4 \pm 18.8 \mu \mathrm{m}$ vs. $205.7 \pm 23.9 \mu \mathrm{m})(P<0.01)$.

\section{Discussion}

Our present findings indicate that the offspring mice coming from late pregnancy mice exposed to a $500 \mathrm{mG}$ $50 \mathrm{~Hz}$ developed myelogenic leukemia with chronic exposure. A major focus of EMF research during the past 20 years has been to determine whether EMFs might increase the risk of cancer, particularly childhood leukemia. In human study, Wertheimer and Leeper first reported that exposure to ELF-EMF could increase the risk of childhood leukemia in 1979 [2]. Other reports showed an increased risk of acute and chronic myelogenous leukemia and acute lymphoblastic leukemia in children [12, 13]. Moreover, 
Table 1 Various organs weights (g) in B6C3F1 male and female mice between control group and 500 mG exposed group

\begin{tabular}{|c|c|c|c|c|c|c|c|c|}
\hline Sex & Group & No. of mice & Heart & Lung & Liver & Spleen & Kidney & Testis or ovary \\
\hline Male & Control & 30 & $0.22 \pm 0.01$ & $0.29 \pm 0.01$ & $2.46 \pm 0.09$ & $0.14 \pm 0.01$ & $0.36 \pm 0.05$ & $0.12 \pm 0.03$ \\
\hline Male & $500 \mathrm{mG}$ exposed & 24 & $0.22 \pm 0.01$ & $0.29 \pm 0.02$ & $1.89 \pm 0.07 * *$ & $0.13 \pm 0.01$ & $0.32 \pm 0.09$ & $0.11 \pm 0.01 *$ \\
\hline Female & Control & 30 & $0.17 \pm 0.01$ & $0.25 \pm 0.01$ & $1.93 \pm 0.07$ & $0.16 \pm 0.01$ & $0.22 \pm 0.03$ & $0.006 \pm 0.001$ \\
\hline Female & $500 \mathrm{mG}$ exposed & 24 & $0.17 \pm 0.01$ & $0.24 \pm 0.01$ & $1.75 \pm 0.07 * *$ & $0.19 \pm 0.01$ & $0.22 \pm 0.03$ & $0.008 \pm 0.001$ \\
\hline
\end{tabular}

$* P<0.05, * * P<0.01$

Table 2 Various organs weights ( $\mathrm{g}$ ) in B6C3F1 male and female mice [standardized with the average body weight (50 g)] between control group and $500 \mathrm{mG}$ exposed group

\begin{tabular}{|c|c|c|c|c|c|c|c|c|}
\hline Sex & Group & No. of mice & Heart & Lung & Liver & Spleen & Kidney & Testis or ovary \\
\hline Male & Control & 30 & $0.23 \pm 0.01$ & $0.30 \pm 0.01$ & $2.52 \pm 0.09$ & 0.14 & 0.37 & 0.12 \\
\hline Male & $500 \mathrm{mG} \mathrm{e}$ & 24 & $0.25 \pm 0.01$ & $0.34 \pm 0.02$ & $2.26 \pm 0.08^{* *}$ & $0.15 \pm 0.01$ & $0.37 \pm 0.09$ & $0.12 \pm 0.01$ \\
\hline emale & Control & 30 & $0.16 \pm 0.01$ & $0.24 \pm 0.01$ & $1.86 \pm 0.07$ & $0.16 \pm 0.01$ & $0.21 \pm 0.03$ & $0.006 \pm 0.001$ \\
\hline Female & $500 \mathrm{mG}$ exposed & 24 & $0.17 \pm 0.01$ & $0.24 \pm 0.01$ & $1.77 \pm 0.07 *$ & $0.19 \pm 0.01$ & $0.22 \pm 0.03$ & $0.008 \pm 0.001$ \\
\hline
\end{tabular}

$* P<0.05, * * P<0.01$

Table 3 Incidence of tumors in B6C3F1 mice between control group and $500 \mathrm{mG}$ exposed group

\begin{tabular}{|c|c|c|c|c|c|}
\hline \multirow[t]{2}{*}{ Location } & \multirow[t]{2}{*}{ Tumor } & \multicolumn{2}{|l|}{ Male } & \multicolumn{2}{|l|}{ Female } \\
\hline & & $500 \mathrm{mG}$ & Control & $500 \mathrm{mG}$ & Control \\
\hline Total number of $\mathrm{B} 6 \mathrm{C} 3 \mathrm{~F} 1$ mice & & 24 & 30 & 42 & 32 \\
\hline \multirow[t]{2}{*}{ Haematopoietic organ } & Chronic myelogenous leukemia & 0 & 0 & $3(7 \%)$ & 0 \\
\hline & Malignant lymphoma & 0 & 0 & 0 & 0 \\
\hline \multirow[t]{3}{*}{ Liver } & Hepatocellular carcinoma & $2(8 \%)$ & $4(13 \%)$ & 0 & 0 \\
\hline & Adenomatous hyperplasia & $6(25 \%)$ & $7(23 \%)$ & 0 & 0 \\
\hline & Haemangioma & $3(13 \%)$ & 0 & 0 & 0 \\
\hline Gastrointestinal tract & Gastric or intestinal tumor & 0 & 0 & 0 & 0 \\
\hline \multirow[t]{2}{*}{ Lung } & Adenocarcinoma & $2(8 \%)$ & $2(7 \%)$ & 0 & $1(3 \%)$ \\
\hline & Adenoma & 0 & $1(3 \%)$ & 0 & 0 \\
\hline Eye & Harderian gland adenoma & 0 & $1(3 \%)$ & 0 & 0 \\
\hline Skin & Eccrine adenocarcinoma & 0 & 0 & $1(2 \%)$ & 0 \\
\hline Ovary & Cystic adenoma & 0 & 0 & $1(2 \%)$ & $1(3 \%)$ \\
\hline Uterus & Stromal sarcoma & 0 & 0 & $1(2 \%)$ & 0 \\
\hline Testis & Adenoma & 0 & $1(3 \%)$ & 0 & 0 \\
\hline
\end{tabular}

results of dozens of increasingly sophisticated studies and the 2 pooled analyses have reported a doubling of risk for children exposed to magnetic fields $>0.3-0.4 \mu \mathrm{T}$ compared with children exposed to fields $<0.1 \mu \mathrm{T}[14,15]$. The Danish case control study concluded that there was no significant association of calculated exposures $>0.2 \mu \mathrm{T}$ with childhood cancers, but the fields $>0.4 \mu \mathrm{T}$ showed an association with major childhood cancers [16]. Epidemiologic studies have repeatedly shown small associations between measures of residential power-line magnetic fields and childhood leukemia. The possibility that these associations are caused by confounders, however, cannot be ruled out [17]. However, few animal tests showed the association between chronic myelogenous leukemia and electromagnetic fields. The natural incidence of chronic myelogenous leukemia is low in $\mathrm{B} 6 \mathrm{C} 3 \mathrm{~F} 1$ mice. In our results, chronic myelogenous leukemia was not found in control group, but was found in bone marrow of 3 female exposed mice. Here we showed a slight increase in risk for chronic myelogenous leukemia. Several studies have been reported that people who worked in electrical occupations had higher than expected rates of some types of cancer, such as leukemia, brain tumors, prostate cancer, testicular cancer, and male breast cancer [18-20]. Recent 
Fig. 3 Tumors in organ of $\mathrm{B} 6 \mathrm{C} 3 \mathrm{~F} 1$ mice in the control and exposed group.

A Representative images of the liver tumor (gross appearance and histology) in control and EMF exposed mice. Arrows indicate the tumor node. Histology (H\&E staining) shows hepatocellular carcinoma (HCC). B Chronic myelogenous leukemia in EMF exposed mice. $a$ Bone marrow, $b$ Liver
A
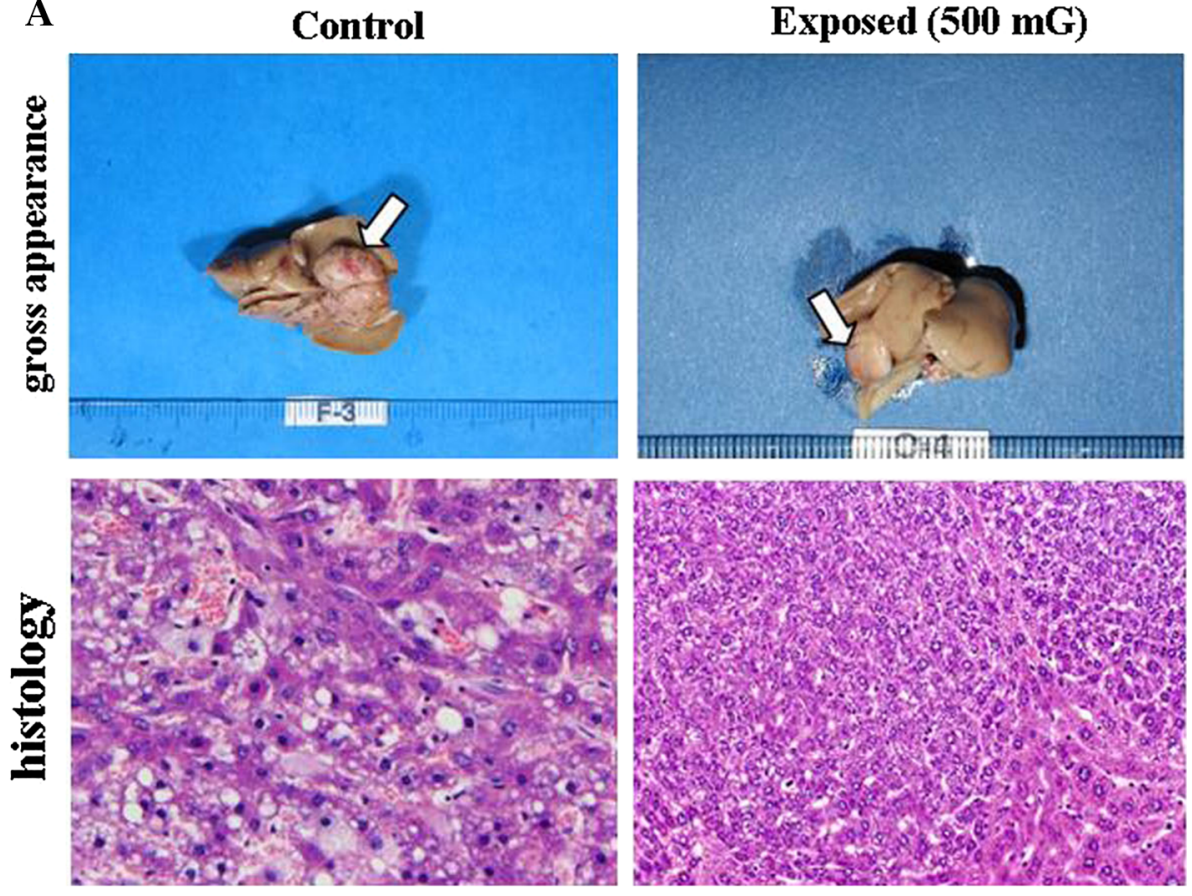

B

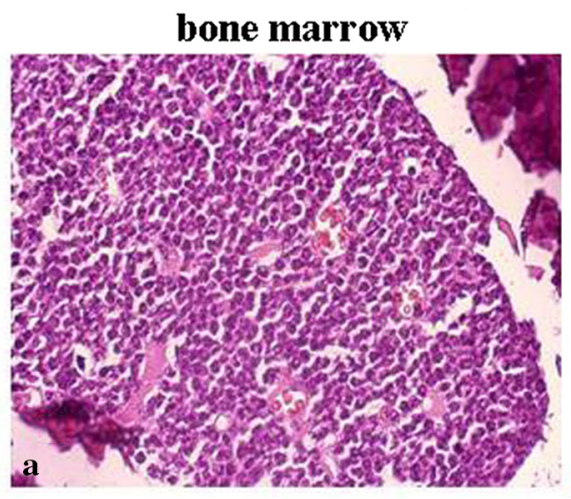

Exposed (500 mG)

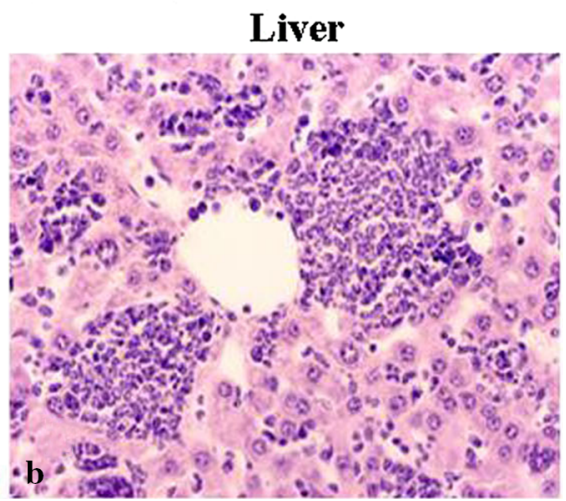

Table 4 Histological examination of seminiferous tubules diameter in $\mathrm{B} 6 \mathrm{C} 3 \mathrm{~F} 1$ mice between control group and $500 \mathrm{mG}$ exposed group

\begin{tabular}{lll}
\hline Group & No of mice & $\begin{array}{l}\text { Size of the seminiferous } \\
\text { tubules diameter }\end{array}$ \\
\hline $500 \mathrm{mG}$ exposed & 24 & $197.4 \pm 18.8^{* *}$ \\
Control & 30 & $205.7 \pm 23.9$ \\
\hline
\end{tabular}

$* * P<0.01$

studies have also associated RF-EMF emissions from wireless phones with risk of brain tumors [21]. However, there is no correlation between the risk for other types of cancer and EMF exposure in our studies. In the other studies of carcinogenicity in $\mathrm{B} 6 \mathrm{C} 3 \mathrm{~F} 1$ mice, no significant difference was detected in the incidence of tumors between $50 \mathrm{~Hz}$ sham and $0.5 \mathrm{mT}$ groups, or $50 \mathrm{~Hz}$ sham and $5 \mathrm{mT}$ groups [7]. If the electromagnetic field acts as promoter of carcinogenesis, it is critical to know whether the agent directly injures the cells of fetal or child/adult mice. Here we could not show the relationship between tumor promotion and electromagnetic field. In fact, early development of tumors was not detected, and spontaneous developing tumor of $\mathrm{B} 6 \mathrm{C} 3 \mathrm{~F} 1$ mice was seen during this test. The agent might act on child or adult mice rather than fetus.

Tumor initiators such as chemical carcinogens, radiation, UV light, or free radicals cause direct damage to DNA. The concepts of initiation, promotion, and sequential accumulation of mutations prompt the consideration of two major pathways whereby an environmental agent such as EMF might cause cancer [22]. Many researches showed the molecular mechanism of effects of magnetic field on the 
biological matter. EMF induces oxidative stress and proliferation through cytosolic $\mathrm{Ca}^{2+}$ influx in human leukemia cells and induces mutation by high-density at DNA synthesis phase in human melanoma cell line [23, 24]. Magnetic field also induces DNA strand breaks in rat brain cells [25]. Other reports showed that ELF fields alone do not damage chromosomal DNA, and direct leukaemogenic activity therefore, seems, unlikely [26]. Although the energy associated with environmental EMFs is too low to cause direct changes to the structure of DNA, EMFs might affect the production of agents such as free radicals, which themselves can react with DNA, or other agents that cause chromosomal damage, instigating translocation by inducing DNA breaks or formation of unnatural DNA structures [22]. Chicken embryos exposed to a continuous-wave $1.25 \mathrm{GHz}$ radiofrequency electromagnetic field shows the increased temperature changes [27]. Moreover, increased expression of heat shock protein (HSP) in magnetic field has been shown [28]. HSPs function as molecular chaperones which facilitate the synthesis and folding of proteins and participate in protein assembly, export, turn-over and regulation. Under stressful conditions such as heat shock, $\mathrm{pH}$ shift or hypoxia, increased expression of HSPs protect the cell by stabilizing unfolded proteins, giving the cell time to repair or re-synthesize damaged proteins. Recently, the relation to HSP and many human tumors have been reported [29]. Altered proliferation of cells after EMF exposure has been observed in a number of studies in vitro. An increase in cell cycle progression of human lymphocytes exposed to $5 \mathrm{mT}(50 \mathrm{~Hz})$ was shown [30]. Animal study has shown a possible copromoter capacity of EMF on tumor growth [31].

Our results also showed that the sizes of seminiferous tubules of the (Table 4 and Fig. 4) EMF exposed group mice were significantly smaller than the control group mice. Some studies have shown that the effect of EMF on fertility by cell phone use negatively affects sperm quality in men [9]. In contrast, exposure of Sprague-Dawley rats to a $60 \mathrm{~Hz}$ EMF at field strengths of up to $500 \mu \mathrm{T}$ from day 6 of gestation to day 21 of lactation did not produce any detectable alterations in offspring spermatogenesis and fertility [11]. The different results may use different animals and choose different exposure time.

Some reports also showed the mechanism of the magnetic field on the biological matter. EMF inhibited MnSOD expression in the rat testis and induced oxidative stress on heart, lung, testis and liver tissues and testicular apoptosis [32-34]. Related animal study has also shown that exposure to ELF induced males mice spermatagonial cells apoptosis [35]. In hormone level studies, exposure of animals to $50 \mathrm{~Hz}, 0.5 \mathrm{mT}$ ELF-EMF for 30 days had no appreciable effect on testosterone level as compared to sham exposed animals [36]. However, we observed that serum testosterone level of exposed rats to $50 \mathrm{~Hz}, 25 \mu \mathrm{T}$ ELF-EMF for 18 weeks was

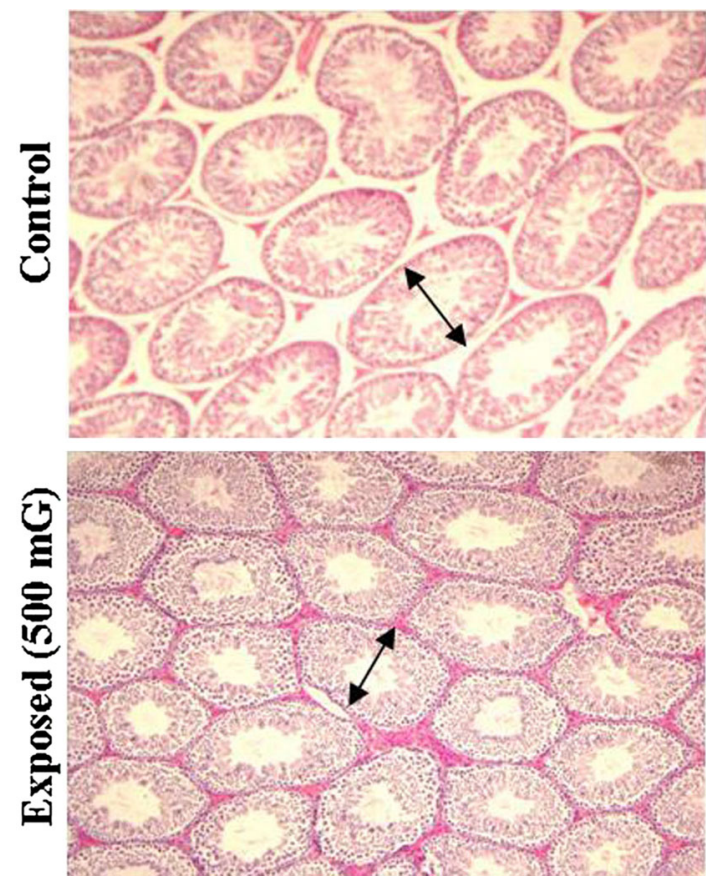

Fig. 4 Seminiferous tubules of the controls groups and the EMF exposed groups $\mathrm{B} 6 \mathrm{C} 3 \mathrm{~F} 1$ male mice. The diameters (double-headed arrow) of the seminiferous tubules were measured using light microscopy

associated with a significant decrease after 6 and 12 weeks of exposure [37]. Our result showed that EMF exposure can weaken reproduction ability. We also need to further examine the alternation at the molecular level in carcinogenicity of leukemia and to identify the cause of effect of fertility by EMF exposed. In conclusions, this study shows the effects of extremely low-frequency electromagnetic field on the tumor promotion process and fertility in mice.

Acknowledgments This research was supported in part by The National Natural Science Foundation of China (No. 81460411 and 81160256) and in part by the Important Research Grant from the Prefectural University of Hiroshima, Hiroshima Tsuchiya General Hospital, Hiroshima. We thank them for their technical and materials assistance.

Conflict of interest The authors declare that they have no conflict of interest.

\section{References}

1. Bediz CS, Baltaci AK, Mogulkoc R, et al. Zinc supplementation ameliorates electromagnetic field-induced lipid peroxidation in the rat brain. Tohoku J Exp Med. 2006;208:133-40.

2. Wertheimer N, Leeper E. Electrical wiring configurations and childhood cancer. Am J Epidemiol. 1997;109:273-84.

3. Greenland S, Kheifets L. Designs and analyses for exploring the relationship of magnetic fields to childhood leukaemia: a pilot project for the Danish National Birth Cohort. Scand J Public Health. 2009;37:83-92. 
4. Heifets L, Ahlbom A, Crespi CM, et al. Pooled analysis of recent studies on magnetic fields and childhood leukaemia. Br J Cancer. 2010;103:1128-35.

5. Savitz DA, Wachtel H, Barner FA, et al. Case-control study of childhood cancer and exposure to $60-\mathrm{Hz}$ magnetic fields. Am J Epidemiol. 1988;128:21-38.

6. Floderus B. Occupational exposure to electromagnetic fields in relation to leukemia and brain tumors: a case-control study in Sweden. Cancer Causes Control. 1993;4:465-76.

7. Otaka Y, Chida T, Yamagishi Y, et al. Carcinogenicity test in B6C3F1 mice after parental and prenatal exposure to $50 \mathrm{~Hz}$ magnetic fields. Bioelectromagnetics. 2002;23:206-13.

8. Fam WZ, Mikhal El. Lymphoma induced in mice chronically exposed to very strong low-frequency electromagnetic field. Cancer Lett. 1966;105:257-69.

9. Gutschi T, Mohamad AI-Ali B, Trummer H, et al. Impact of cell phone use on men's semen parameters. Andrologia. 2011;43:312-6.

10. Rajaei F, Borhani N, Mashayekhi F, et al. Effects of extremely low-frequency electromagnetic field on fertility and heights of epithelial cells in pre-implantation stage endometrium and fallopian tube in mice. J Chin Integr Med. 2010;8:56-60.

11. Chung MK, Lee SJ, Kim YB, et al. Evaluation of spermatogenesis and fertility in F1 male rats after in utero and neonatal exposure to extremely low frequency electromagnetic fields. Asian J Androl. 2005;7:189-94.

12. Linet MS, Hatch EE, Kleinerman RA, et al. Residential exposure to magnetic fields and acute lymphoblastic leukemia in children. N Engl J Med. 1997;337:1-7.

13. Muscat JE, Gallagher RP, Theriault G, et al. Power-frequency electric and magnetic fields and risk of childhood leukemia in Canada. Am J Epidemiol. 1999;149:831-42.

14. Ahlbom A, Day N, Feychting M, et al. A pooled analysis of magnetic field and childhood leukemia. Br J Cancer. 2000;83:692-8.

15. Greenland S, Sheppard A, Kaune W, et al. A pooled analysis of magnetic fields, wire codes, and childhood leukemia. Childhood Leukemia-EMF Study Group. Epidemiology. 2000;11:624-34.

16. Olsen JH, Nielsen A, Schulgen G. Residence near high voltage facilities and risk of cancer in children. Br Med J. 1993;307:891-4.

17. Savitz DA. Health effects of electric and magnetic fields: are we done yet? Epidemiology. 2003;14:15-7.

18. Yousif L, Blettner M, Hammer GP, et al. Testicular cancer risk associated with occupational radiation exposure: a systematic literature review. J Radiol Prot. 2010;30:389-406.

19. Charles LE, Loomis D, Shy CM, et al. Electromagnetic fields, polychlorinated biphenyls, and prostate cancer mortality in electric utility workers. Am J Epidemiol. 2003;157:683-91.

20. Matanoski GM, Breysse PN, Elliott EA. Electromagnetic field exposure and male breast cancer. Lancet. 1991;337:737.

21. Hardell L, Carlberg M. Sing the Hill viewpoints from 1965 for evaluating strengths of evidence of the risk for brain tumors associated with use of mobile and cordless phones. Rev Environ Health. 2013;28:97-106.

22. Lacy-Hulbert A, Metcalfe JC, Hesketh R. Biological responses to electromagnetic fields. FASEB J. 1998;12:395-420.

23. Nazioglu M, Cig B, Dogan S, et al. 2.45-GHz wireless devices induces Oxidative stress and proliferation through cytosolic $\mathrm{Ca}^{2+}$ influx in human leukemia cancer cells. Int J Radiat Biol. 2012;88:449-56.

24. Miyakoshi J, Kitagawa K, Takebe H. Mutation induction by highdensity, 50-Hz magnetic fields in human MeWo cells exposed in the DNA synthesis phase. Int J Radiat Biol. 1997;71:75-9.

25. Lai H, Singh NP. Magnetic-field-induced DNA strand breads in brain cells of the rat. Environ Health Perspect. 2004;112:687-94.

26. Murphy JC, Kaden DA, Warren J, et al. International Commission for Protection Against Environmental Mutagens and Carcinogens. Power frequency electric and magnetic fields: a review of genetic toxicology. Mutat Res. 1993;296:221-40.

27. Thalau HP, Raczek J, Marx B, et al. Temperature changes in chicken embryos exposed to a continuous-wave $1.25 \mathrm{GHz}$ radiofrequency electro-magnetic field. Radiat Res. 2013;159:685-92.

28. Tokalov SV, Gutzeit HO. Weak electromagnetic fields $(50 \mathrm{~Hz})$ elicit a stress response in human cells. Environ Res. 2004;94:145-51.

29. Yang Q, Liu S, Tian Y, et al. Methylation-associated silencing of the heat shock protein 47 gene in human neuroblastoma. Cancer Res. 2004;64:4531-8.

30. Antonopoulos A, Yang B, Stamm A, et al. Cytological effects of $50 \mathrm{~Hz}$ electromagnetic fields on human lymphocytes in vitro. Mutat Res. 1995;346:151-7.

31. Löscher W, Mevissen M. Animal studies on the role of 50/60-Hertz magnetic fields in carcinogenesis. Life Sci. 1994;54:1531-43.

32. Zeng LH, Ji XT, Zhang YJ, et al. MnSOD expression inhibited by electromagnetic pulse radiation in the rat testis. Electromagn Biol Med. 2011;30:205-18.

33. Esmekaya MA, Ozer C, Seyhan N. $900 \mathrm{MHz}$ pulse-modulated radiation induces oxidative stress on heart, lung, testis and liver tissues. Gen Physiol Biophys. 2011;30:84-9.

34. Saygin M, Caliskan S, Karahan N, et al. Testicular apoptosis and histopathological changes induced by $2.45 \mathrm{GHz}$ electromagnetic field. Toxicol Ind Health. 2011;27:455-63.

35. Kim YW, Kim HS, Lee JS, et al. Effects of $60 \mathrm{~Hz} 14$ microT magnetic field on the apoptosis of testicular germ cell in mice. Bioelectromagnetics. 2009;30:66-72.

36. Taherianfard M, Bahaddini A, Keshtkar S, et al. Effect of extremely low frequency electromagnetic field and GABAA receptors on serum testosterone level of male rats. Int J Endocrinol Metab. 2013;11:e11029.

37. Al-Akhras MA, Darmani H, Elbetieha A. Influence of $50 \mathrm{~Hz}$ magnetic field on sex hormones and other fertility parameters of adult male rats. Bioelectromagnetics. 2006;27:127-31. 